\title{
The Application of External Fields to the Manufacturing of Novel Dense Composite Master Alloys and Aluminum-Based Nanocomposites
}

\author{
SERGEY A. VOROZHTSOV, DMITRY G. ESKIN, JAVIER TAMAYO, \\ ALEXANDER B. VOROZHTSOV, VLADIMIR V. PROMAKHOV, \\ ARTEM A. AVERIN, and ANTON P. KHRUSTALYOV
}

\begin{abstract}
The possibility of producing dense and concentrated master alloys containing nanosized $\mathrm{Al}_{2} \mathrm{O}_{3}$ by shock-wave compacting is demonstrated. Different conditions of shock-wave process are discussed. The data of master alloys characterization are presented. The nanostructured master alloys have high density and are convenient for metallurgical handling. It is found that the use of such a master alloy with nanoceramic particles facilitates the particle introduction into the aluminum melt. The ultrasonic treatment performed during and after the introduction of the master alloy into the melt further leads to uniform distribution of strengthening nanoparticles and improvement of alloy strength and ductility. Experimental results are shown and discussed.
\end{abstract}

DOI: $10.1007 / \mathrm{s} 11661-015-2850-3$

(C) The Minerals, Metals \& Materials Society and ASM International 2015

\section{INTRODUCTION}

MODERN development of aerospace and automotive industry calls for materials with high specific strength. Traditionally used aluminum alloys currently reached the limit of their properties and new lightweight materials such as Al-based metal-matrix composites (MMC) and metal-matrix nanocomposites (MMNC) are under development. ${ }^{[1,2]}$ However, manufacturing of MMC and MMNC faces a number of challenges. The first is the selection of a technological route, e.g., powder metallurgy, liquid-metal processing, preform impregnation. The second is the selection of reinforcing phases and their morphology, e.g., particles or fibers. The third is the selection of means to improve the introduction and dispersion of the reinforcements inside the matrix.

The liquid metal route offers the most versatile scope of applications as the final part can be cast in various molds, whereas the powder metallurgy and preformbased routes are limited in size and shape of the

SERGEY A. VOROZHTSOV, Head of the Laboratory of Nanotechnology for Metallurgy, and ANTON P. KHRUSTALYOV, Postgraduate Student, are with the National Research Tomsk State University, Tomsk, Lenin Str. 36, 634050, Russia, and also with the Institute of Strength Physics and Materials Science SB RAS, Tomsk, 634021, Russia. DMITRY G. ESKIN, Professor, is with the BCAST, Brunel University London, Uxbridge UB8 3PH, UK, and also with the National Research Tomsk State University. Contact e-mail: dmitry.eskin@brunel.ac.uk JAVIER TAMAYO, Research Fellow, is with the BCAST, Brunel University London. ALEXANDER V. VOROZHTSOV, Professor, Head of the Laboratory of High Energy and Special Materials, and VLADIMIR V. PROMAKHOV, Research Fellow, are with the National Research Tomsk State University. ARTEM A. AVERIN, Head of the Section of Explosive Materials, is with Federal Research \& Production Centre "Altai", Russia, Biysk, Socialisticheskaya Str. 1, 659322, Russia.

Manuscript submitted December 3, 2014.

Article published online March 20, 2015 manufactured parts. Therefore in this research we focus on the introduction of the reinforcement into the liquid metal with subsequent casting.

Particulate reinforcement seems to be more universal than with fibers. The latter tend to form bundles and maybe more suitable for the preform route. Particle reinforcement blocks dislocation and grain boundary motion and effectively strengthens the material at room and elevated temperatures. ${ }^{[3]}$ In this case the reinforcement effect is determined by the particle size, their volumetric concentration, and spatial distribution. It was suggested in a number of works that high-modulus, thermally stable compounds such as $\mathrm{Al}_{2} \mathrm{O}_{3}$ and $\mathrm{SiC}$ could be most suitable as reinforcing particles. ${ }^{[4-6]}$ In the case of optimal reinforcement loading and distribution the following can be achieved for light alloys: wider working temperature range, significantly improved strength, Young's modulus, wear resistance, and reduced thermal expansion. ${ }^{[4,7]}$ However, MMC usually require a considerable loading of 5 to 20 pct with particles up to $10 \mu \mathrm{m} .{ }^{[7]}$ There is evidence that the reduction of the average particle size to several tens of nanometers will make it possible to enhance the properties of Al-based MMNCs at a much lower loading. ${ }^{[3,8]}$

It is well documented ${ }^{[5,9-11]}$ that direct introduction of ceramic particles (especially nanosized ones) into liquid metal is very challenging due to the fact that they are prone to agglomeration and flotation caused by their poor wettability by the liquid metal. This problem can be solved in three ways: (1) using pre-treatment or coating of the particles, ${ }^{[4]}$ (2) using pre-fabricated master alloys, ${ }^{[5]}$ and (3) using the impact of external fields on the metallic melt and particle agglomerates. ${ }^{[2,10]}$ In this paper we concentrated on the last two means. The method of master alloy synthesis that provides high density, optimal controlled content, and phase composition of reinforcing particles is of great importance. 
Various techniques were used in the past, e.g., mixing of nanoparticles with aluminum powder followed by extrusion, ${ }^{[12]}$ melting under pressure, ${ }^{[13]}$ or sintering under pressure. ${ }^{[14]}$ The application of such master alloy makes the introduction of particles into the melt easier but does not solve the problem of their agglomeration and dispersion. ${ }^{[14]}$ The application of external fields (e.g., ultrasonic cavitation) can facilitate wetting of the particles, breaking down the particle agglomerates, and homogeneous distribution of the particles throughout the melt volume and, eventually, throughout the billet structure. ${ }^{[5,6,10]}$ Shock waves were suggested for compacting powders and even making nanocomposite materials through a powder metallurgy route..$^{[15-17]}$ In this paper we combine the application of shock-wave (SW) compaction to master alloy production that assures the formation of high-density concentrated nanocomposites ${ }^{[18]}$ with the application of ultrasound during introduction of the master alloy in the melt that facilitates dispersion of nanoparticles throughout the melt volume.

\section{EXPERIMENTAL}

\section{A. Shock-Wave Compaction of Master Alloys}

1. Selection of explosives for shock-wave compaction of powders

Pressure required for consolidation of a certain material is determined by its hardness $P \approx \mathrm{HV} \cdot{ }^{[15]}$ For example, a pressure of $1 \mathrm{GPa}$ is required for compaction of Al powder with a regular particle size $(<160 \mu \mathrm{m})$ and hardness $\mathrm{HV}=100 .^{[19]}$ On the other hand, the impulse of pressure or the detonation velocity is equally important for achieving high-density compaction.

The minimum detonation velocity required for compaction of metallic particles depends on the hardness of the particles HV and the density of the explosive used $\rho_{\mathrm{e}}$ as $^{[15]}$ :

$$
V_{\mathrm{d}}=2 \sqrt{\frac{1.2 \times 9.8 \times \mathrm{HV}}{\rho_{\mathrm{e}}}}
$$

A simple estimate using typical densities of the explosives between 1 and $1.3 \mathrm{~g} / \mathrm{cm}^{3}$ gives the detonation velocity required for compaction $\mathrm{Al}$ powder about $1000 \mathrm{~m} / \mathrm{s}$, which is two-three times lower than the real detonation velocities achieved by commercial explosives as shown in Table I.

The pressure in the detonation wave $P_{\mathrm{H}}$ is functionally related to density $\rho_{\mathrm{e}}$ and detonation velocity $V_{\mathrm{d}}$ of the explosive used (Table I) and can be calculated as ${ }^{[16]}$ :

Table I. Characteristic Data of Some Common Explosives

\begin{tabular}{lcccc}
\hline Explosive & $\rho_{\mathrm{e}}, \mathrm{g} / \mathrm{cm}^{3}$ & $V_{\mathrm{d}}, \mathrm{m} / \mathrm{s}$ & $P, \mathrm{GPa}$ & Ref. \\
\hline Ammonit-1 & 1.25 & 3500 & 3.8 & {$[19]$} \\
Carbonit & 1.05 & 1600 & 0.7 & {$[19]$} \\
Uglenit & 1.2 & 2200 & 1.5 & {$[20]$} \\
\hline
\end{tabular}

$$
P_{\mathrm{H}} \approx 1 / 4\left(\rho_{\mathrm{e}} \times\left(V_{\mathrm{d}}\right)^{2}\right)
$$

Some industrial explosives show the ability to produce the required pressure (about $1 \mathrm{GPa}$ ) that should be sufficient to obtain fully compacted material (see Table I).

As a result of this estimate, "Uglenit"-an industrial coal mine explosive with bulk density of $1.10-1.25 \mathrm{~g} /$ $\mathrm{cm}^{3}$ and detonation rate $V_{\mathrm{d}}=2100-2500 \mathrm{~m} / \mathrm{s}$ (according to technical specifications) - was used as explosive. TNT equivalent was equal to 0.45 and the fugacity value was $130 \mathrm{~cm}^{3}$. The estimated value of $P_{\mathrm{H}}$ is $1.4-1.5 \mathrm{GPa}$ as assessed by Eq. [2].

\section{Experimental technique}

Figure 1(a) shows the scheme for shock-wave compaction of an aluminum tube with a powder mixture. A tube was positioned onto a pad using a centering cardboard ring. The gap was also filled with the compacted explosive. A mixture of $10 \mathrm{wt}$ pct $\mathrm{Al}_{2} \mathrm{O}_{3}$ nanoparticles $(<100 \mathrm{~nm})$ synthesized using the Electrical Explosion of Wire (EEW) method ${ }^{[21]}$ and $90 \mathrm{wt}$ pct ASD6 Al powder $(<50 \mu \mathrm{m})$ was prepared in a tumble mixer with steel mixing bodies. The mixture was then placed in a 10-mm diameter aluminum (99.7 pct Al) tube that was sealed from both sides with aluminum stoppers. The aluminum tube with powder mixture was centered by means of a second ring, and then Uglenit explosive compacted to $\rho=1.25 \mathrm{~g} / \mathrm{cm}^{3}$ was put into the cup $50 \mathrm{~mm}$ above the tube. A standard electric detonator was installed in the middle of this layer at the $20 \mathrm{~mm}$ depth. The total mass of explosive was $860 \mathrm{~g}$. The assembly was put into the blast chamber on a metal plate, detonator was connected to initiation circuit, the chamber was closed, and the assembly was detonated. The samples before and after SW compaction are shown on the Figure 1(b).

\section{B. Production of Aluminum-Based Composite Materials}

An aluminum alloy Al-4 wt pct $\mathrm{Cu}$ was melted in a graphite crucible with a total melt volume of $750 \mathrm{~g}$. The ultrasonic processing was performed using a $5-\mathrm{kW}$ water-cooled magnetostrictive transducer with a working frequency of $17.5 \mathrm{kHz}$. A conical sonotrode with a working null-peak amplitude of about $30 \mu \mathrm{m}$ was made of niobium. Ultrasonic degassing was performed at the melt temperature of $1003 \mathrm{~K}\left(730{ }^{\circ} \mathrm{C}\right)$ for 1 minute. Then, the SW-master alloy $\mathrm{Al}-10$ wt pet $\mathrm{Al}_{2} \mathrm{O}_{3}$ was introduced into the ultrasonic cavitation zone in the melt, directly under the sonotrode. After the introduction of the master alloy, the melt was treated with ultrasound for further 2 minutes at $1003 \mathrm{~K}\left(730^{\circ} \mathrm{C}\right)$. Then the obtained mixture was poured at $983 \mathrm{~K}$ $\left(710{ }^{\circ} \mathrm{C}\right)$ into a metallic mold with the cavity size of dia. $30 \times 110 \mathrm{~mm}$. The nominal nanoparticles content in the alloy was $0.1 \mathrm{wt}$ pct. A reference sample was produced using the similar processing parameters but without master alloy introduction. 


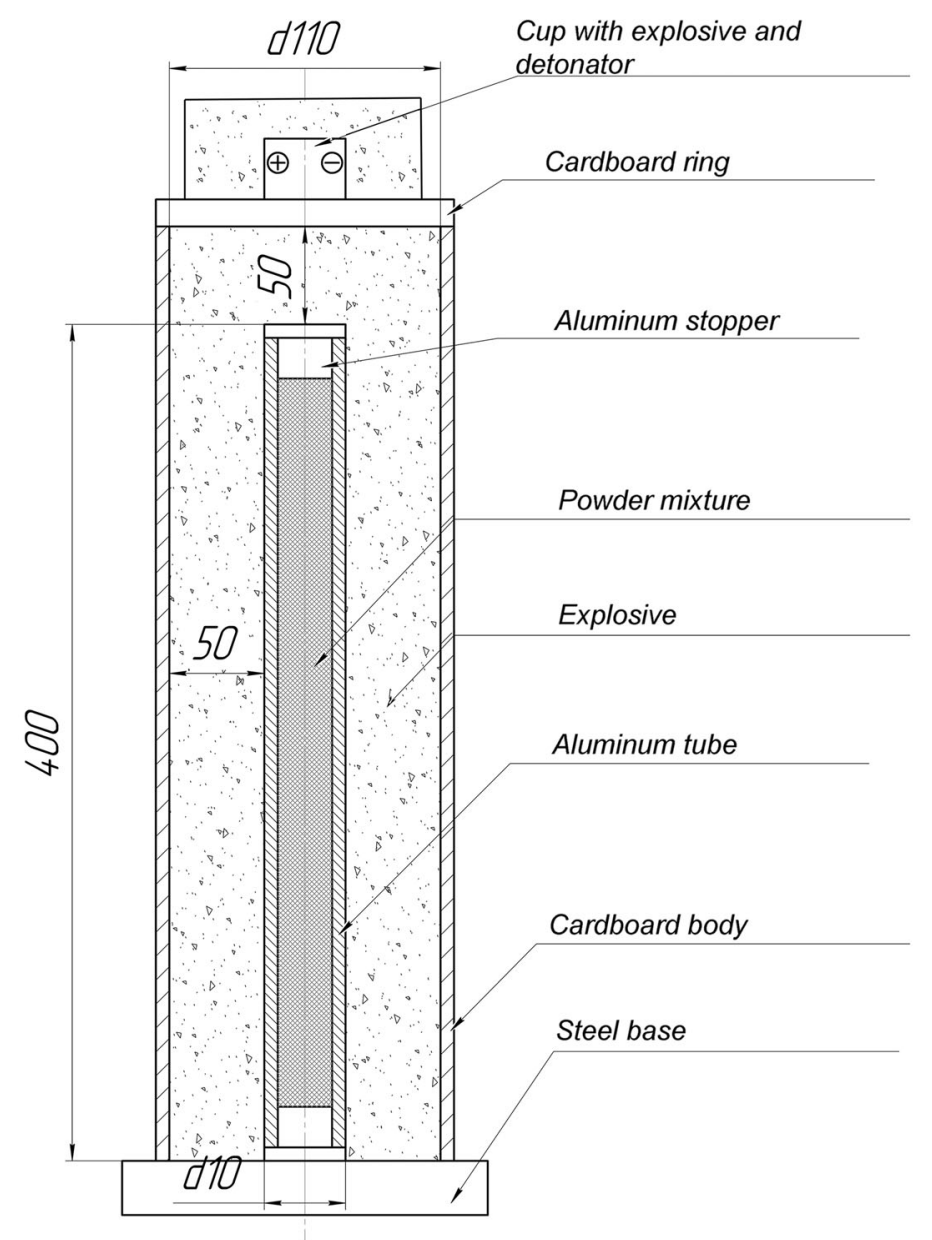

(a)

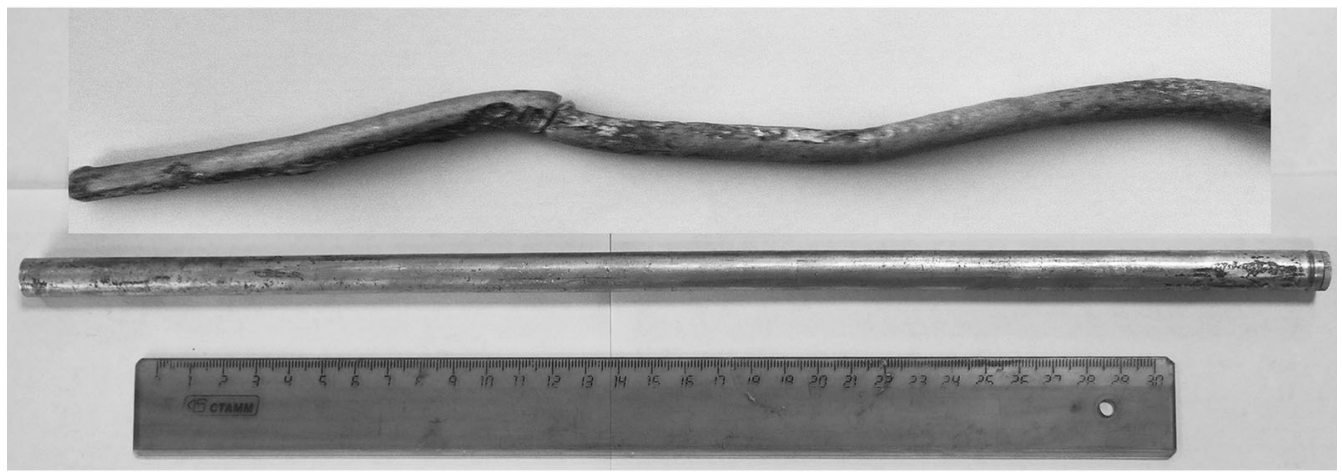

(b)

Fig. 1-The scheme for explosion compaction of aluminum tube with powder mixtures (a) and samples before (bottom) and after SW compaction (above) (b)

\section{Methods of Structure and Properties Investigation}

The starting powders were characterized using a Philips SEM 515 scanning electron microscope (SEM) and JEM 2100 transmission electron microscope (TEM). The particle size for powders was calculated using Mastersizer 2000 particle size analyzer.

Phase composition and structural parameters of the starting powders and obtained composite were studied using a diffractometer with $\mathrm{Cu} K \alpha$ radiation. Step-bystep collection of X-ray patterns was performed in the range $20 \mathrm{deg}<2 \theta<120 \mathrm{deg}$ with $0.02 \mathrm{deg}$ step for structural parameters and with $0.1 \mathrm{deg}$ step for phase composition determination. Phase identification was performed by comparing experimental patterns with ASTM data. The sizes of crystallites were determined using small-angle peaks and microdistortion of crystal 


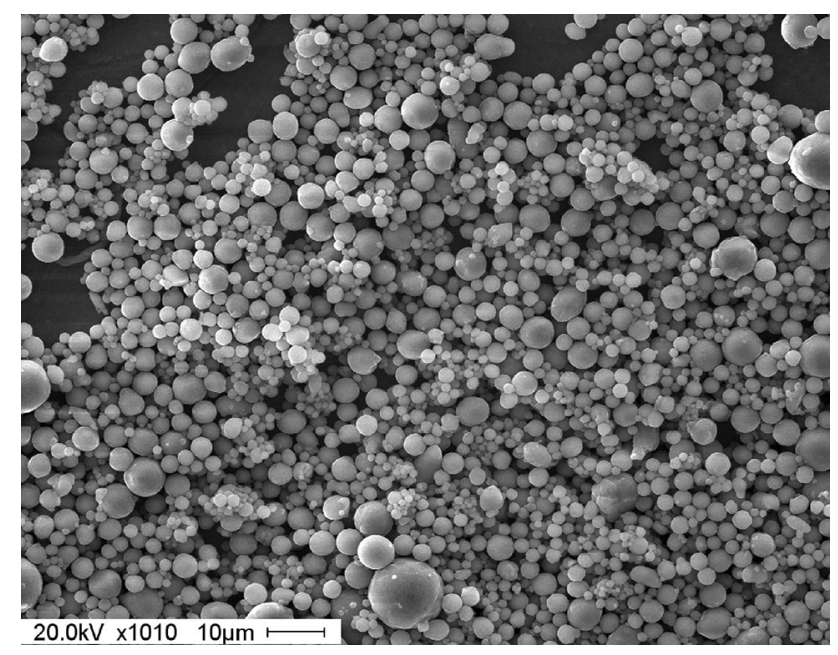

Fig. 2-An SEM image of Al powder.

lattice $\left\langle\varepsilon^{2}\right\rangle^{1 / 2}$ was calculated using widening of reflection at large diffraction angles. ${ }^{[22]}$

The density of the master alloy was determined by the Archimedes method.

Flat tensile samples $1 \mathrm{~mm}$ thick with a gage length of $40 \mathrm{~mm}$ were cut in the vertical cross section from cylindrical castings and tested in a tensile machine Instron 3369 at a strain rate of $2 \times 10^{-4} \mathrm{~s}^{-1}$. Guaranteed frame stiffness for this machine corresponds to $250 \mathrm{kN}$ load, a load accuracy is 0.5 pet of indicated load. Three samples were tested for each condition. Microhardness was measured using Nano Indenter G200/XP tester with a load of $250 \mathrm{~g}$. At least three samples were tested for each condition and the average data are reported.

\section{RESULTS AND DISCUSSION}

\section{A. Powders}

A SEM image of the Al powder for master alloy synthesis is shown in Figure 2. The Al particles have a regular spherical shape. The average particle size was $18 \mu \mathrm{m}$. The specific surface area of the powder was $0.7 \mathrm{~m}^{2} / \mathrm{g}$. An XRD analysis showed that the size of coherent scattering region (i.e., defect-free area of the crystal) in Al powder was $110 \mathrm{~nm}$ with the crystal lattice parameter $0.40479 \mathrm{~nm}$ and the crystal lattice microdistortion $\left\langle\varepsilon^{2}\right\rangle^{1 / 2} 2.9 \times 10^{-3}$

$\mathrm{X}$-ray phase analysis shows that $\mathrm{Al}_{2} \mathrm{O}_{3}$ nanopowders produced using EEW method completely consist of the mixture of amorphous and $\gamma-\mathrm{Al}_{2} \mathrm{O}_{3}$ phase. The BET surface area is equal to $35-40 \mathrm{~m}^{2} / \mathrm{g}$. A typical TEM image of particles is shown in Figure 3(a). The particles in the powder are separated even being in agglomerates and have a regular spherical shape. Nanoparticle size distribution bar chart is shown in Figure 3(b). Average particle size $\tilde{\mathrm{a}}_{\mathrm{n}}=36 \mathrm{~nm}$.

\section{B. SW-Master Alloy}

The microstructure of the concentrated Al-10 wt pct $\mathrm{Al}_{2} \mathrm{O}_{3}$ master alloy after shock-wave compaction is

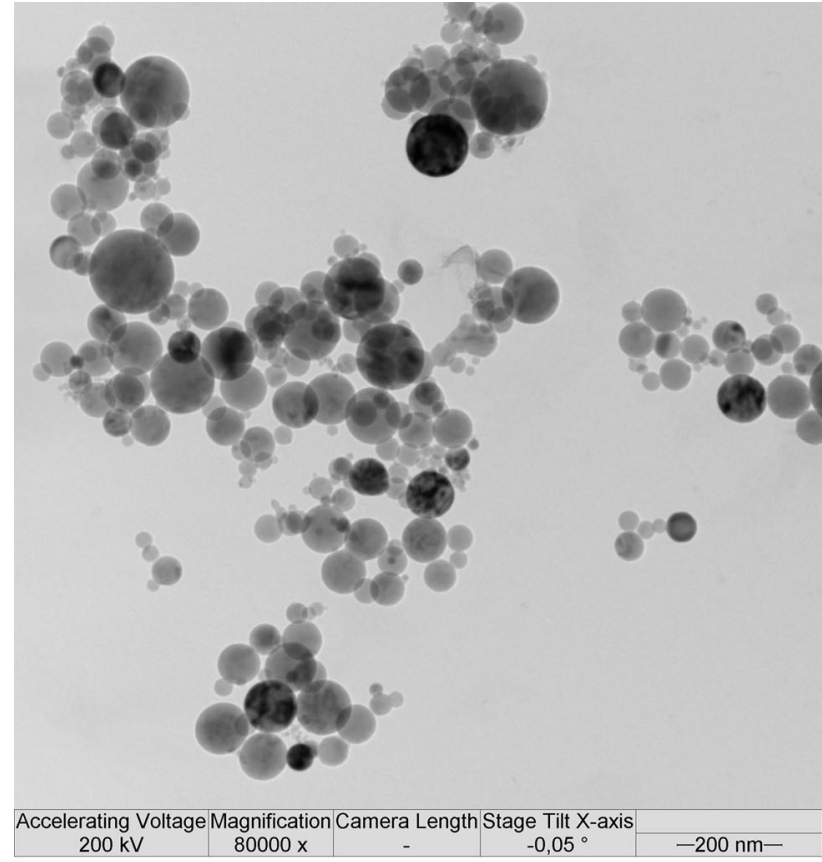

(a)

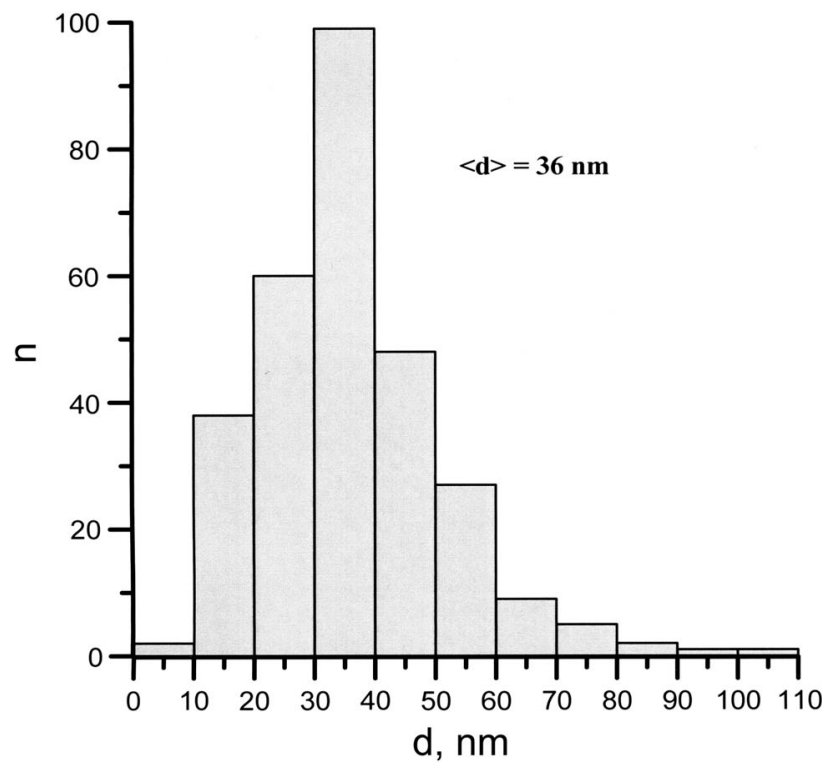

(b)

Fig. 3-A TEM image of $\mathrm{Al}_{2} \mathrm{O}_{3}$ powder $(a)$ and particle size distribution $(b)$

shown in Figure 4. The material has a fine grain structure and the grain size between 2 and $10 \mu \mathrm{m}$. The density of master alloy is close to the theoretical density of $\mathrm{Al}$ and ranges between 2.5 and $2.7 \mathrm{~g} / \mathrm{cm}^{3}$.

An XRD analysis showed that the coherent scattering region size of $\mathrm{Al}$ for the master alloy was $300 \mathrm{~nm}$. Apparently the increased size of defect-free structural elements of $\mathrm{Al}$ is a result of dynamic recrystallization which takes place in the process of explosive loading of powder materials. The change of crystallite size is accompanied by the reduction of the crystal lattice 
parameter to $4.0420 \AA$ and the microdistortion of crystal lattice $\left\langle\varepsilon^{2}\right\rangle^{1 / 2}$ to $5.7 \times 10^{-4}$. The reduction in crystal parameters can be explained by high impact

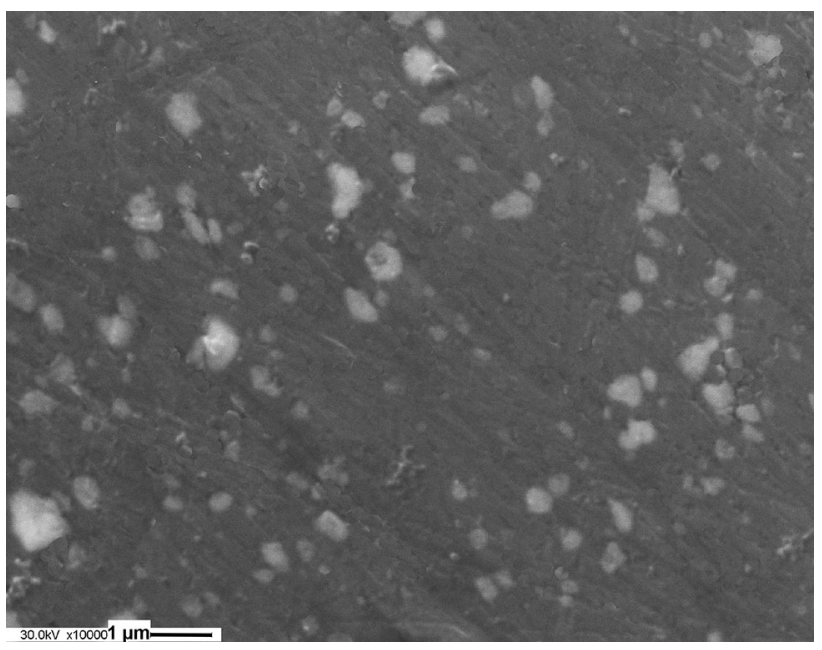

Fig. 4-An SEM image of a master alloy $\mathrm{Al}-10$ wt pet $\mathrm{Al}_{2} \mathrm{O}_{3}$ after shock-wave compaction. compression of powders in the process of dynamic synthesis.

\section{Al-Based Composite Alloy with $\mathrm{Al}_{2} \mathrm{O}_{3}$ Nanoparticles}

$\mathrm{Al}_{2} \mathrm{O}_{3}$-EEW nanoparticles are promising as reinforcing particles for introduction into an $\mathrm{Al}$ alloy. In this study, the introduction of particles through the concentrated SW-master alloy assisted by ultrasonic melt processing was obviously easier than adding loose particles, even when they were wrapped in an Al foil and introduced along with mechanical stirring. ${ }^{[11]}$ No obvious rejection of particles to the surface of the melt or to the crucible walls/bottom was observed. This procedure is also much safer for the personnel involved as no loose particles could escape into the environment.

The microstructure of an $\mathrm{Al}-4$ wt pet $\mathrm{Cu}-0.1 \mathrm{wt}$ pct $\mathrm{Al}_{2} \mathrm{O}_{3}$ alloy is given in Figures 5(a) and (b). $\mathrm{Al}_{2} \mathrm{O}_{3}$ particle agglomerates as well as evenly distributed spherical particles and small pores up to $10 \mu \mathrm{m}$ in size are present in the as-cast structure. Note that the grain size and general microstructural appearance of the alloy did not change. The residual porosity of as-cast alloys and composites did not exceed 2 pct.

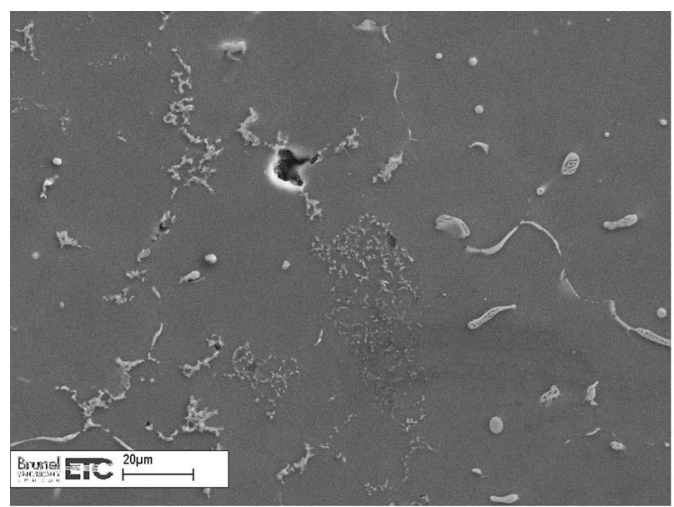

(a)

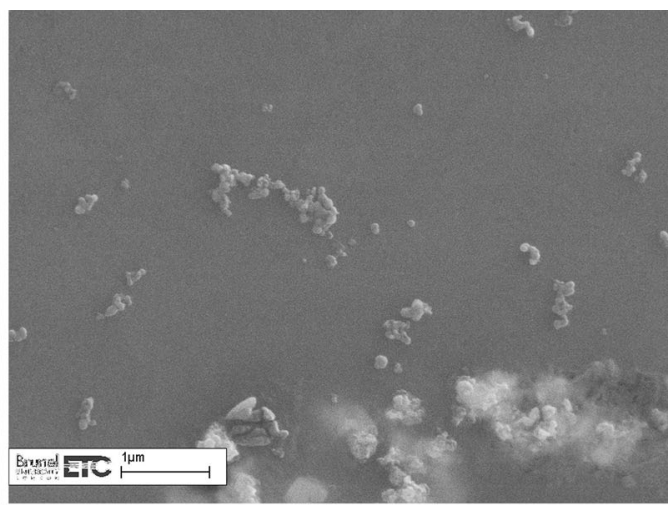

(b)

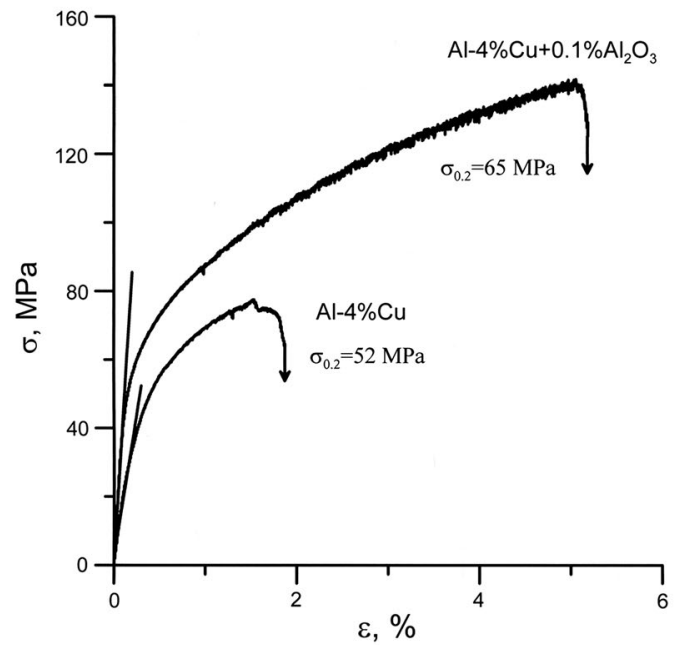

(c)

Fig. 5-SEM images of the as-cast composite material Al-4 wt pet $\mathrm{Cu}-0.1$ wt pet $\mathrm{Al}_{2} \mathrm{O}_{3}(a, b)$ and stress-strain diagrams of this composite material in comparison with the matrix material $(c)$. 
The stress-strain tensile curves for produced samples are given in Figure 5(c). Apparently, the introduction of 0.1 pct $\mathrm{Al}_{2} \mathrm{O}_{3}$ nanoparticles into the alloy leads to simultaneous improvement of yield strength, ultimate tensile strength, and ductility. Moreover, alloy hardness also increases from 57 to $71 \mathrm{HV}$.

The simultaneous increase in strength and ductility can be attributed to a more homogeneous strain distribution upon deformation. It was suggested ${ }^{[23]}$ that the presence of particles inside the grain envelope might lead to the deviation of a potential crack from the grain boundary into the bulk of the grain and to a larger involvement of the matrix in the deformation and fracture. Globular and uniformly distributed particles might result in the maximum plastic deformation of the matrix during crack propagation ${ }^{[23]}$ and prevented the formation of multiple slip-band piles. ${ }^{[24]}$ In addition, a larger amount of particles increased the amount and density of interphase boundaries in the structure, reducing the role of grain boundaries as stress concentrators and crack initiators. As a result the fracture mode was reported to change from intergranular (or ductile with large dimples) to transgranular with fine dimples with the resulting improvement of fracture toughness. ${ }^{[23,24]}$ The applicability of these general considerations to the observed improvement of mechanical properties needs further investigation.

Although certain improvement in the mechanical properties has been achieved, the structure of the composite material is still far from being optimal with persisting nanoparticle agglomerates and associated porosity. The procedure of composite material manufacturing should be further optimized to assure more complete deagglomeration of particles.

\section{CONCLUDING REMARKS}

The possibility to synthesize a concentrated master alloy with 10 wt pet $\mathrm{Al}_{2} \mathrm{O}_{3}$ nanoparticles by shock-wave compaction is demonstrated. The introduction of such a master alloy in the aluminum melt with simultaneous ultrasound treatment makes the introduction procedure safer and more reproducible, leads to satisfactory distribution of nanoparticles in the structure and to the improvement in the yield strength, ultimate tensile strength, and ductility of the resultant MMNC with 0.1 wt pct reinforcement. Further work is needed on optimizing the technology of master alloy introduction into the liquid matrix.

\section{ACKNOWLEDGEMENTS}

The work was financially supported by the Ministry of Education and Science of the Russian Federation within the framework of the Federal Target Program. Agreement No. 14.578.21.0025 (Unique identifier RFMEFI 57814X0025). A.B. Vorozhtsov, S.A. Vorozhtsov, J. Tamayo and D.G. Eskin acknowledge financial support from the Exomet Project (which is co-funded by the European Commission in the 7th Framework Programme (contract FP7-NMP3-LA-2012-280421), by the European Space Agency and by the individual partner organizations).

\section{REFERENCES}

1. A.D. Moghadam, B.F. Schultz, J.B. Ferguson, E. Omrani, P.K. Rohatgi, and N. Gupta: JOM, 2014, vol. 66, pp. 872-81.

2. W.H. Sillekens, D.J. Jarvis, A. Vorozhtsov, V. Bojarevics, C.F. Badini, M. Pavese, S. Terzi, L. Salvo, L. Katsarou, and H. Dieringa: Metall. Mater. Trans. A, 2014, vol. 45A, pp. 3349-61.

3. S.-C. Tjong, ed., Nanocrystalline Materials, 2nd edn., Elsevier, London, 2014, pp. 286-294.

4. A. Mortensen and I. Jin: Int. Mater. Rev., 1992, vol. 37 (3), pp. $101-28$.

5. Y. Yang and X. Li: J. Manuf. Sci. Eng., 2007, vol. 129, pp. 497501

6. H. Choi, M. Jones, H. Konishi, and X. Li: Metall. Mater. Trans. $A, 2012$, vol. 43A, pp. 738-46.

7. D.J. Lloyd: Int. Mater. Rev., 1994, vol. 39 (1), pp. 1-23.

8. Y.-C. Kang and S.L.-I. Chan: Mater. Chem. Phys., 2004, vol. 85, pp. 438-43.

9. Y. Yang, J. Lan, and Z. Li: Mater. Sci. Eng. A, 2004, vol. 380, pp. 378-83.

10. G.I. Eskin and D.G. Eskin: Ultrason. Sonochem., 2003, vol. 10, pp. 297-301.

11. J. Tamayo-Ariztondo, S.V. Madam, E. Djan, D.G. Eskin, N.H. Babu, and Z. Fan: in Light Metals, J. Grandfield, ed., TMS (The Minerals, Metals \& Materials Society)/Wiley, Warrendale, 2014, pp. $1411-15$.

12. R. Casati, X. Wei, K. Xia, D. Dellasega, A. Tuissi, E. Villa, and M. Vedani: Mater. Des., 2014, vol. 64, pp. 102-09.

13. M. Estruga, L. Chen, H. Choi, X. Li, and S. Jin: ACS Appl. Mater. Interfaces, 2013, vol. 5, pp. 8813-819.

14. S. Kandemir, H.V. Atkinson, D.P. Weston, and S.V. Hainsworth: Metall. Mater. Trans. A, 2014, vol. 45A, pp. 5782-98.

15. R. Prümmer: Materialwiss. Werkstofftech., 1989, vol. 20 (12), pp. $410-15$.

16. M.A. Meyers and S.L. Wang: Acta Metall., 1988, vol. 36, pp. 925 36.

17. N. Alba-Baena, W. Salas, and L.E. Murr: in Carbon Nanotubes, J.M. Marulanda, ed., InTech, Rijeka, 2010, pp. 635-64.

18. S.N. Kulkov, S.A. Vorozhtsov, V.F. Komarov, and V.V. Promakhov: Russ. Phys. J., 2013, vol. 56, pp. 85-89.

19. R.A. Pruemmer, T.B. Bhat, K.S. Kumar, and K. Hokamoto: Explosive Compaction of Powders and Composites, CRC, Boca Raton, 2006

20. Commercial Explosive Uglenit. GOST RU 52036-2003. The AllRussian state standard R52036-2003.

21. Y.F. Ivanov, M.N. Osmonoliev, V.S. Sedoi, V.A. Arkhipov, S.S. Bondarchuk, A.B. Vorozhtsov, A.G. Korotkikh, and V.T. Kuznetsov: Propellants Explos. Pyrotech., 2003, vol. 28 (6), pp. 319-33.

22. G.K. Williamson and W.H. Hall: Acta Metall., 1953, vol. 1, pp. $22-31$

23. N.A. Belov: Met. Sci. Heat Treatm., 1995, vol. 37, pp. 237-42.

24. Z. Chen, T. Wang, Y. Zheng, Y. Zhao, H. Kang, and L. Gao: Mater. Sci. Eng. A, 2014, vol. 605, pp. 301-09. 